\title{
INDENTIFKASI JENIS TUMBUHAN DI LOKASI PERTAMBANGAN NIKEL PT. CMMI (CAHAYA MODERN METAL INDUSTRI) KABUPATEN KONAWE SULAWESI TENGGARA
}

\section{IDENTIFICATION OF PLANTS SPECIES AT NICKEL MINING PT. CMMI (MODERN LIGHT METAL INDUSTRY) KONAWE DISTRICT SOUTHEAST SULAWESI}

\author{
Indrawati $^{(1)}$, Sri Ambardini ${ }^{(2)}$, Harmonika Nyiliantri ${ }^{(3)}$, \\ ${ }^{(1,2)}$ Dosen Program Studi, Jurusan Biologi FMIPA Universitas Halu Oleo Kendari \\ ${ }^{(3)}$ Mahasiswa Jurusan Biologi FMIPA Universitas Halu Oleo Kendari \\ -(1)Corresponding Email Author : indrawatiansar@yahoo.com
}

\begin{abstract}
ABSTRAK
Tujuan penelitian ini untuk mengetahui jenis-jenis tumbuhan yang tumbuh di lokasi pertambangan nikel PT. CMMI (Cahaya Modern Metal Industri) Kabupaten Konawe, Sulawesi Tenggara. Prosedur penelitian dimulai dengan penetapan lokasi penelitian, kemudian dilanjutkan koleksi tumbuhan dan identifikasi jenis-jenis tumbuhan. Penelitian dilakukan dengan metode jelajah pada 3 stasiun pengamatan (stasiun I, stasiun II dan stasiun III). Hasil penelitian teridentifikasi 51 jenis tumbuhan yang tergolong dalam divisi Spermatophyta dan Pteridophyta. Divisi Spermatophyta terdistribusi dalam kelas Dicotyledoneae sebanyak 15 suku, kelas Monocotyledoneae sebanyak 2 suku, Divisi Pteridophyta terdistribusi dalam kelas Pteridopsida sebanyak 2 suku, yaitu Polypodiaceae dan Schizaeaceae. Stasiun I ditemukan sebanyak 40 jenis, stasiun II ditemukan sebanyak 15 jenis dan stasiun III ditemukan sebanyak 32 jenis.
\end{abstract}

Kata Kunci : Identifikasi, Tumbuhan,Tambang nikel, PT. CMMI

\begin{abstract}
The purpose of this research was to find out the species of plants that grow in the nickel mining location of PT CMMI (Modern Light Metal industry) Konawe district, Southeast Sulawesi. Study Procedure begins with the determination of the area of research, collections of plants dan identification of plant species. Results of the study identified 51 species of plants that are classified indivisins Spermatophyta and Pteridophyta. The Divisio Spermatophyta distributed class Dicotyledoneae 15 family and the class Monocotyledoneae 2 family. The Divisin Pteridophyta distributed in class Pteridopsida as much as 2 family, Schizaeaceae and Polypodiaceae. The station I found as much as 40 species, station II found as much as 15 species and station III found as much as 32 species.
\end{abstract}

Keyword : Identification, Plant, Nickel mine , PT. CMMI 


\section{PENDAHULUAN}

\section{Latar Belakang}

PT. CMMI adalah salah satu perusahan pabrik pertambangan pengolah dan pemurnian nikel yang memulai produksi padatanggal 23 Desember2013. Pabrik ini mengolah nikel menjad I bahan setengah jadi berupa nikel pigiron (NPI) dengan kapasitas 25.000ton pertahun (PUSLITBANG TEKMIRA, 2015). Kawasan pertambangan ini memanfaatkan sumber daya alam yang terletak di sekitar pemukiman, perkebunan dan lahan pertanian masyarakat di Desa Wonua Morone, Kecamatan Puriala, Kabupaten Konawe Sulawesi Tenggara.

Riswan, dkk.,

menyatakan bahwa berbagai dampak yang ditimbulkan akibat adanya penambangan nikel adalah meningkatnya jumlah aktivitas pembukaan hutan dan pembangunan pemukiman untuk para pekerja yang dapat menimbulkan dampak negatif terhadap lingkungan. Aktivitas tersebut dapat merusak habitat, flora dan fauna, plasma nutfah, sistem tata air, menurunkan produktivitas lahan dan mengancam kelangsungan hidup jenis di habitat tersebut. Kegiatan pertambangan biasanya dilakukan dengan cara pembukaan hutan, pengikisan lapisan-lapisan tanah, pengerukan dan penimbunan.

Berdasarkan observasi awal, kondisi lahan setelah dibukanya kawasan pertambangan nikel PT. CMMI mengalami perubahan yang sangat signifikan terhadap kondisi lingkungan biotik, terutama bagi tumbuhan yang terdapat pada lahan tersebut. Hal ini dikarenakan tanah yang menjadi topsoil tergali sangat dalam mengakibatkan sulitnya tumbuhan untuk tumbuh di kawasan pertambangan, meskipun demikian terdapat beberapa tumbuhan yang mampu bertahan hidup pada kondisi habitat yang kritis tersebut.

Tumbuhan memiliki peranan penting dalam meremediasi lahan pertambangan. Hal ini dikarenakan tumbuhan memiliki potensi sebagai hiperakumulator yang dapat digunakan untuk meremediasi lingkungan yang tercemar(Juhaeti, dkk., 2005). Potensi ini dapat dimanfaatkan untuk mencari jenis-jenis tumbuhan yang pontesial untuk fitoremediasi, sehingga perlu adannya identifikasi tumbuhan di lokasi pertambangan untuk memberikan informasi data dasar dan gambaran lokasi yang diwakili oleh 3 stasiun pengamatan di Pertambangan nikel PT. CMMI Kabupaten Konawe Sulawesi Tenggara. 


\section{METODE PENELITIAN}

\section{Alat dan Bahan}

Alat dan bahan penelitian ini meliputi GPS, kamera digital, lux meter, termometer, oven, sasak, kertas karton, alkohol 70\%, etiket tempel, etiket gantung dan kantung plastik.

\section{Prosedur Penelitian}

\section{Survei dan penentuan Lokasi Penelitian}

Survei awal bertujuan untuk mendapatkan gambaran umum dan menentukan lokasi penelitian. Lokasi atau stasiun penelitian ditetapkan dengan memperhatikan sturktur dan komposisi vegetasi yang dianggap dapat mewakili seluruh komunitas tumbuhan di lokasi penelitian. Ditetapkan 3 stasiun penelitian, Stasiun I (pada posisi 04\%1'12,7" LS dan $122^{\circ} 06^{\prime} 17,5^{\prime \prime}$ BT) berada di lokasi sekitar kantor PT. CMMI, lokasi ini telah terjadi suksesi selama 7 tahun. Stasiun II (pada posisi $04^{\circ} 01^{\prime} 08,0$ " LS dan $122^{\circ} 06^{\prime} 28,4^{\prime \prime}$ BT), berada di lokasi tumpukan sisa kerukan tanah tambang dimana lokasi ini ditinggalkan dan terjadi suksesi selama 3 tahun. Stasiun III (pada posisi $04^{\circ} 01^{\prime} 08,3^{\prime \prime}$ LS dan $122^{\circ} 06^{\prime} 30,6^{\prime \prime}$ BT), berada di lokasi pintu masuk pertambangan sebagai akses jalan menuju lokasi pertambangan.

\section{Koleksi tumbuhan}

Kegiatan koleksi tumbuhan pada penelitian ini menggunakan cara koleksi kering. Spesimen berupa bagian batang/ranting berdaun dengan bunga atau buah untuk tumbuhan berbiji. Koleksi tumbuhan paku dengan mengambil semua bagian paku, batang atau rimpang, daun (ental) tumbuhan paku untuk keperluan identifikasi.

\section{Pembuatan herbarium}

Pembuatan spesiem herbarium menggunakan teknik pembuatan herbarium kering. Bahan-bahan tumbuhan yang dijadikan spesimen kering terlebih dahulu diawetkan dengan alkohol 70\%. Spesimen selanjutnya diproses melalui pengeringan dengan menggunakan oven pada suhu $50-60^{\circ} \mathrm{C}$. Herbarium yang telah kering kemudian ditempel (mounted) pada kertas karton dengan ukuran yang telah disediakan.

\section{Identifikasi}

Identifikasi tumbuhan mengacu pada Flora untuk Sekolah di Indonesia (Steenis, dkk., 1997) dan Hand Book On Weed Identification (Naidu, 2012).

\section{Gambaran Data Lingkungan}

Data lingkungan yang diamati meliputi suhu (tanah dan udara), kelembaban (tanah dan udara) dan intensitas cahaya. 
HASIL DAN PEMBAHASAN

\section{Parameter Lingkungan}

Hasil pengukuran faktor lingkungan pada setiap stasiun pengamatan di lokasi pertambangan nikel PT. CMMI (Cahaya Modern Metal Industri) Kabupaten Konawe Sulawesi Tenggara dapat dilihat pada Tabel 1.

Tabel 1. Parameter Lingkungan di Lokasi Pertambangan Nikel PT. CMMI Kabupaten Konawe Sulawesi Tenggara.

\begin{tabular}{|c|c|c|c|c|}
\hline \multirow{2}{*}{ No } & \multirow{2}{*}{$\begin{array}{c}\text { Parameter } \\
\text { Lingkungan }\end{array}$} & \multicolumn{3}{|c|}{ Stasiun Pengamatan } \\
\hline & & 1 & 2 & 3 \\
\hline 1. & $\begin{array}{l}\text { Kelembaban } \\
\text { Udara (\%) }\end{array}$ & 79 & 93 & 86 \\
\hline 2. & Suhu Udara $\left({ }^{\circ} \mathrm{C}\right)$ & 32 & 32 & 32 \\
\hline 3. & $\begin{array}{l}\text { Kelembaban } \\
\text { Tanah (\%) }\end{array}$ & 79 & 93 & 87 \\
\hline 4. & $\begin{array}{ll}\text { Suhu Tanah } \\
\left({ }^{\circ} \mathrm{C}\right)\end{array}$ & 29 & 34 & 34 \\
\hline 5. & $\begin{array}{l}\text { Intensitas } \\
\text { Cahaya (cd) }\end{array}$ & 96.500 & 10.180 & 99.800 \\
\hline
\end{tabular}

Ket : I :Lokasi sekitar kantor, II : Lokasi tumpukan sisa kerukan tanah tambang dan III : Lokasi pintu masuk pertambangan.

Suhu udara, suhu tanah, kelembaban udara dan kelembaban tanah merupakan komponen iklim mikro yang sangat mempengaruhi pertumbuhan tumbuhan dan masingmasing saling berkaitan mewujudkan keadaan lingkungan optimal bagi tumbuhan. Menurut Noorhadi dan Utomo (2002), parameter iklim mikro yaitu suhu tanah, kelembaban tanah, suhu udara, dan kelembaban udara

Lokasi pertambangan nikel PT. CMMI Kabupaten Konawe, Sulawesi Tenggara memiliki suhu udara yang relatif sama pada ke-3 stasiun yaitu $32^{\circ} \mathrm{C}$. Suhu udara di Lokasi pertambangan nikel PT. CMMI Kabupaten Konawe Sulawesi Tenggara masuk dalam kategori tidak optimum untuk pertumbuhan. Menurut Barbour, dkk.,(1999) suhu optimum untuk produktivitas tumbuhan adalah $15^{\circ} \mathrm{C}$ dan $25^{\circ} \mathrm{C}$ terutama untuk fotosintesis tumbuhan.

Suhu tanah terutama suhu ekstrimnya akan mempengaruhi perkecambahan dan aktivitas akar. Mekanisme pertukaran panas di permukaan tanah akan sangat menentukan proses-proses yang terjadi di udara dekat permukaan tanah (Sudaryono, 2009). Berdasarkan hasil pengukuran rata-rata suhu tanah pada tiga stasiun berkisar antara $29^{\circ} \mathrm{C}$ dan $34^{\circ} \mathrm{C}$. Suhu tanah yang tinggi dapat menyebabkan dehidrasi yang dapat menghambat pertumbuhan tumbuhan (Tirta, 2012).

Kelembaban udara adalah jumlah uap air yang dikandung dalam satuan udara, sedangkan kelembaban tanah adalah jumlah uap air yang dikandung dalam tanah (Noorhadi dan Utomo, 2002). Berdasarkan hasil pengukuran rata-rata kelembaban udara pada tiga stasiun berkisar antara $79 \%, 93 \%$ dan $86 \%$ Fungsi kelembaban yang tinggi bagi tumbuhan 
salah satunya untuk menghindari penguapan yang terlalu tinggi (Tirta, 2012).

Rata-rata intensitas cahaya pada stasiun I, II, dan III yaitu 96.500 cd, $99.800 \mathrm{~cd}$ dan $10.180 \mathrm{~cd}$. Intensitas cahaya di stasiun I lebih rendah dibandingkan stasiun II dan III, hal ini dikarenakan berada pada lingkungan yang ternaungi oleh pohon-pohon yang sengaja ditanam oleh pengelola pertambangan nikel PT. CMMI. Intensitas cahaya pada stasiun II dan III memiliki kondisi intensitas cahaya yang tidak jauh berbeda, lokasi stasiun ini dekat dengan aktivitas pertambangan dan lalu lintas kendaraan tambang, dengan kondisi tanah yang gersang, berbatu dan merupakan tumpukan sisa kerukan tanah tambang.

\section{Identifikasi Tumbuhan}

Hasil identifikasi tumbuhan yang terdapat di lokasi pertambangan nikel PT. CMMI Kabupaten Konawe, Sulawesi Tenggara, teridentifikasi 51 jenis tumbuhan yang tergolong dalam 2 divisi yaitu Spermatophyta dan Pteridophyta. Divisi Spermatophyta terdistribusi dalam kelas Dicotyledoneae sebanyak 15 suku, yaitu: Amaranthaceae, Malvaceae, Asteraceae, Euphorbiaceae, Fabaceae, Lamiaceae,

Melastomaceae,
Rubiaceae, suku Myrtaceae, Passifloraceae, Solanaceae, suku Urticaceae, suku Verbenaceae, Scorphurlanaceae, suku Tiliaceae dan kelas Monocotyledoneae sebanyak 2 suku yaitu Cyperaceae dan Poaceae.

Suku Poaceae merupakan suku dengan jumlah jenis terbanyak yaitu 10 jenis dan diikuti suku Asteraceae dengan jumlah jenis 8 jenis. Hal ini disebabkan karena suku Poaceae memiliki daya adaptasi yang tinggi, distribusi luas dan mampu tumbuh pada lahan kering maupun tergenang sebagaimana Griscom, dkk., (2006) menyatakan jenis dari suku Poaceae memiliki kemampuan menyebar dengan cepat karena biji yang ringan dan mudah terbawa angin. Selain itu, sistem perakaran rizome dalam tanah dan stolon di atas tanah menyebabkan kemampuan ekspansinya tinggi dan dapat mencapai kawasan yang jauh.

Persebaran jenis suku Asteraceae dipenaruhi oleh variasi morfologinya, terutama perbungannya, pada bunga tabung atau bunga tengah yang menyusun perbungaan, terdapat pappus. Pappusi tidak gugur dan tetap ditemukan ketika bunga telah berkembang menjadi buah. Buah yang memiliki pappus berupa rambut-rambut halus mudah untuk disebarkan oleh angin. Biji dalam buah akan tumbuh 
dengan baik pada kondisi yang sama (Kohli, dkk., 2009).

Divisi Pteridophyta terbagi dalam Kelas Pteridopsida sebanyak 2 suku, yaitu Schizaeaceae yang terdiri atas jenis Lygodium flexuosum (L.) Sw. dan suku Polypodiaceae terdiri atas Nephrolepis biserrata Schott, Phityrogramma calomelanos Link. dan Pteris vittata L.. Keberadaan tumbuhan paku di lokasi ini didukung oleh faktor lingkungan biotik maupun abiotik di sekitarnya yang telah ditumbuhi jenis tumbuhan Spermatophyta lainnya dan interaksi dengan kondisi iklim mikro (suhu udara, kelembaban udara, intensitas cahaya) sebagaimana pada Tabel 1.

Jenis tumbuhan terbanyak ditemukan pada Stasiun I sebanyak 40 jenis yaitu Amaranthus viridis Hook.f., Ageratum conyzoides L., Blumea lacera (Burm.f.) D.C., Emilia sonchifolia D.C., Eupatorium odoratum L., Mikania micrantha H.B.K., Porophyllum ruderale (Jack) Cass., Synedrella nodiflora Geartn., Vernonia cinerea Less., Croton hirtus L. Herit., Euphorbia hirta L., Phylanthus niruri L., Phyllanthus urinaria L., Phyllanthus virgatus Forst., Alysicarpus vaginalis D.C., Callopogoniummuconoides Desv., Cassia tora (L.) Roxb., Desmodium triflorum D.C., Mimosa pudica L.,
Hyptis capitata Jacq., Sida acuta Burm. F., Borrirea alata Lamk. D.C., Borreria laevis Lamk. Griseb., Scoparia dulcis L., Muntingia calabura L., Fimbristylis annua R. \& S., Andropogon aciculatus Retz., Chloris barbata Sw., Cynodon dactylon Pers., Dactyloctenium aegyptium Richt., Eragrotis amabilis O.K., Digitaria microbachne (Presl) Henr., Echinochioa colona (L.) Link., Eleusine Indica Gaertn., Imperata cilindrica L., Sporobolus indicus L., Paspalum conjigatum P.J. Bergius, Lygodium flexuosum (L.) Sw., Nephrolepis biserrata Schott., Phityrogramma calomelanos Link. dan Pteris vittata L..

Jenis terbanyak kedua ditemukan di stasiun III sebanyak 32 jenis yaitu Ageratum conyzoides L., Blumea lacera (Burm.f.) D.C., Eupatorium odoratum L., Mikania micrantha H.B.K., Porophyllum ruderale (Jack) Cass., Synedrella nodiflora Geartn., Vernonia cinerea Less., Macaranga tanarius (L.) Mull.Arg., Phyllanthus virgatus Forst., Callopogonium muconoides Desv., Desmodium triflorum D.C., Mimosa pudica L., Ceiba pentandra Gaertn. var. Indica Bakh.,Urena lobata L., Melastoma polyantrum Bl., Psidium guajava L., Passiflorafoetida L., Solanum torvum Sw., Trema orientalis BI., Lantana camara L., Stachytarpheta 
jamaicensis Vahl., Andropogon aciculatus Retz., Chloris barbata Sw., Cynodon dactylon Pers., Dactyloctenium aegyptium Richt., Eragrotis amabilis O.K., Eleusine Indica Gaertn., Imperata cilindrica L., Sporobolus indicus L., Paspalum conjigatum P.J. Bergius, Lygodium flexuosum (L.) Sw., Nephrolepis biserrata Schott. dan Pteris vittata L..

Selanjutnya Stasiun II diperoleh 15 jenis yaitu Emilia sonchifolia D.C., Eupatorium odoratum L., Mikania micrantha H.B.K., Macaranga tanarius (L.) Mull. Arg.,Callopogonium uconoides Desv., Mimosa pudica L., Passiflorafoetida L., Passiflora foetida L., Trema orientalis BI., Cynodon dactylon Pers., Digitaria microbachne (Presl) Henr., Eleusine Indica Gaertn., Imperata cilindrica L., Lygodium flexuosum (L.) Sw. dan Phityrogramma calomelanos Link..

Keanekaragaman berbagai jenis flora tergantung dengan keadaan tanah, suhu, ketinggian tempat dan unsur hara yang terdapat dalam tanah. Menurut Steenis, dkk., (2008) tanah yang baru saja dipertinggi dan tempat penuangan tanah biasanya ditumbuhi tumbuhan ruderal. Kondisi ini sesuai dengan keadaan pada stasiun I telah mengalami suksesi. Tumbuhan ruderal antara lain dari marga Amaranthus, Desmodium dan Emilia (Riswan, dkk., 2015).

\section{PENUTUP}

\section{Kesimpulan}

Berdasarkan hasil identifikasi tumbuhan di lokasi pertambangan nikel PT. CMMI, Desa Wonua Morone, Kecamatan Puriala, Kabupaten Konawe, Provinsi Sulawesi Tenggara, teridentifikasi 51 jenis tumbuhan Spermatophyta dan Pteridophyta. Keseluhan jenis terdistribusi di Stasiun I Lokasi sekitar kantor sebanyak 40 jenis, Stasiun II lokasi tumpukan sisa kerukan tanah tambang sebanyak 15 jenis dan Stasiun III Lokasi pintu masuk pertambangan sebanyak 32 jenis.

\section{Saran}

Perlu penelitian lanjut untuk analisis vegetasi keanekaragaman jenis tumbuhan di lokasi pertambangan nikel PT. CMMI, Desa Wonua Morone, Kecamatan Puriala, Kabupaten Konawe Provinsi Sulawesi Tenggara.

\section{DAFTAR PUSTAKA}

Barbour, M.G.,Burk, J.K., and Pitts, W.D., 1999, Terestrial Plants ecology, Third Edition, California, USA.

Griscom, H.P., Griscom, B.W., dan Ashton, M.S., 2006, Pattern and Proses of Forest Succession 
Within Exsperimental Treatment of A Pasture In A Dry Tropikal Region, Yale University New Haven CT., Azuero Peninsula, Panama.

India, Noorhadi dan Utomo, S., 2002, Kajian Volume dan Frekuensi Pemberian Air Terhadap Iklim Mikro pada Tumbuhan Jagung Bayi (Zea mays L.) di Tanah Entisol, Jurnal Sains Tanah, 2(1): 41-44

Juhaeti, T., Syarif F. dan Hidayati, N., 2005, Inventarisasi Tumbuhan Potensial untuk Fitoremediasi Lahan dan Air Terdegradasi Penambangan Emas, Jurnal Biodiversitas, 6(1): 31

Kohli, R.K.,Singh H.P.,Batish,D.R., dan Dogra, K.S., 2009, Invasive Plants and Forest Ecosystem, CRC Press, New York.

Naidu, V.S.G.R., 2012, Hand Book On Weed Identification, Dicertori Of Weed Science Research, Jabalpur,

Pusat Penelitian dan Pengembangan Teknologi Mineral dan Batu Bara, 2015, Evalusi Dampak Pengembangan Smelter di Indonesia (Studi Kasus di Sulawesi Selatan dan Sulawesi Tenggara), Bandung.

Riswan, Harun, U., dan Irsan, C., 2015, Keragaman Flora di Lahan Reklamasi Pasca Tambang Batubara PT. BA Sumatera
Selatan, Jurnal Manusia dan Lingkungan, 22(2): 160

Steenis, C.G.G.J., Hoed G.D., Bloembergen S., dan Eyma, P.J.,1997. Flora untuk Sekolah di Indonesia (Cetakan ke-7), PT. Pradnya Paramita, Jakarta.

Steenis, .C.G.G.J.,HoedG.D.,Bloember genS., dan Eyma,P.J., 2008. Flora (Cetakan ke-12), PT. Pradnya Paramita, Jakarta.

Sudaryono, 2009, Tingkat Kesuburan Tanah Ultisol pada Lahan Pertambangan Batubara Sangatta, Kalimantan Timur, Jurnal Teknik Lingkungan,(3)10: 56

Sugiarti, A., 2017, Identifikasi Jenis Paku-Pakuan (Pteridophyta) di Kawasan Cagar Alam Pagerwunung Darupono Kabupaten Kendal sebagai Media Pembelajaran Sistematika Tumbuhan Berupa Herbarium, Skripsi, Fakultas Sains dan Teknologi Universitas Islam Negeri Walisongo, Semarang.

Tirta, I.G., 2012, Pengaruh Suhu dan Kelembaban Terhadap Laju Pertumbuhan Paphiopedillum javanicum (Reinw. ex Lindl.) Pfitzer, Jurnal Sains dan Teknologi 11(3): 52-55

Tjitrosoepomo, G., 2005, Taksonomi Umum, Gadjah Mada University Press, Yogyakarta. 